\title{
Genotypic and phenotypic analysis of clinical isolates of Staphylococcus aureus revealed production patterns and hemolytic potentials unlinked to gene profiles and source
}

Andreas Roetzer ${ }^{1}$, Guenter Haller ${ }^{1}$, John Beyerly ${ }^{1}$, Christoph B. Geier ${ }^{2}$, Hermann M. Wolf ${ }^{2}$, Corina S. Gruener ${ }^{1}$, Nina Model ${ }^{1}$ and Martha M. Eibl ${ }^{1,2^{*}}$

\begin{abstract}
Background: Nosocomial infections caused by the bacterial pathogen Staphylococcus aureus can lead to serious complications due to the varying presence of secreted toxins. Comparative studies of genomic information and production rates are needed to assess the pathogenic potential of isolated strains. Genotypic and phenotypic profiling of clinical and colonising isolates of $\mathrm{S}$. aureus was used to characterise the release of exotoxins. Blood isolates were compared with colonisation strains to determine similarities and differences of single strains and clusters.

Results: Fifty-one fresh isolates obtained from colonised individuals $(n=29)$ and S. aureus bacteremia (SAB) patients $(n=22)$ were investigated. The prevalence of genes encoding for three cytolysins (alpha/beta/gamma toxin) and twenty-four superantigens (SEA-SEIX) was determined. Isolates exhibited eighteen distinct combinations of superantigens. Sequence analysis identified mutated open reading frames in hla in $13.7 \%$ of all strains, in selw (92.2\%) and in selx (15.7\%). All corrupted genes were associated with specific clonal complexes. Functional assessment of alpha toxin activity by a rabbit erythrocyte lysis assay revealed that supernatants lacking alpha toxin still displayed hemolysis. This was due to the presence of gamma toxin, as proven by inhibition experiments using antisera raised against the respective recombinant proteins. Alpha toxin, SEC, and TSST1 production was quantified by enzymelinked immunosorbent assays on supernatants of all hla, sec, and tst positive isolates. Blood isolates and colonising strains showed comparable amounts of secreted proteins within a wide range. Agr types I to IV were identified, but did not allow a prediction of high or low production rates. In contrast, alpha toxin production rates between distinct clonal complexes clearly differed. Spa typing was performed and revealed thirty-two unique spa gene patterns and eight small clusters comprising nineteen isolates. Recognised spa-typing clusters displayed highly similar production rates.
\end{abstract}

Conclusion: Production rates of the three most prevalent exotoxins varied within both groups of blood isolates and colonising strains. By comparing genotypes and secretion, we found that identical complex gene patterns did not allow predictions of toxin production and function. However, identification of spa typing clusters was suitable to predict similar quantities of released exotoxins.

Keywords: Staphylococcal infection, Exotoxins, Protein quantification, Typing, Hemolysis

\footnotetext{
* Correspondence: office@biomed-research.at

${ }^{1}$ Biomedizinische ForschungsgmbH, Lazarettgasse 19/2, Vienna A-1090,

Austria

${ }^{2}$ Immunology Outpatient Clinic, Schwarzspanierstraße 15, Vienna A-1090,

Austria
} 


\section{Background}

The importance of Staphylococcus aureus as a human pathogen continued to rise in the first decade of this century [1]. Staphylococcal infections can lead to various, often devastating diseases, such as skin abscesses, osteomyelitis, endocarditis, necrotising pneumonia, sepsis and the toxic shock syndrome (TSS) [2]. Despite an increase of infections due to community-acquired methicillin-resistant S. aureus (CA-MRSA) [3], methicillin-sensitive strains (MSSA) still cause the majority of $S$. aureus infections in Western and Northern parts of the European Union [4]. In a long-term study on the epidemiology of TSS in Minnesota (US), MRSA caused only $7 \%$ of all TSS cases [5].

Discussion regarding which virulence factors favor the spread of certain clones in the community is ongoing. Secreted and membrane-associated proteins contribute to virulence of $S$. aureus [6-8]. The majority of virulence factors are encoded in the core genome, which is estimated to include approximately $78 \%$ of the whole genome [9]. However, a prominent group of virulence determinants is sited on vectors such as pathogenic islands (SaPIs) or prophages [10, 11]. Different combinations of these factors might contribute to the broad range of invasion sites and infection outcomes.

The challenging group of exotoxin virulence factors comprises cytolytic toxins and mitogenic superantigen toxins. Members of both have been shown to contribute significantly to the lethal outcome of $S$. aureus infections [12]. The most prominent cytolytic toxin genes encode for pore-forming proteins (alpha toxin and gamma toxin) and are part of the core genome [13]. Alpha toxin is thought to be expressed by all strains, although high and low producers have been described [14]. Similarly, the gamma toxin locus was found in $99 \%$ of all strains [15]. The large group of superantigens (also termed as staphylococcal enterotoxins, SE) is variously spread among clinical isolates [16]. Altogether, twenty-four superantigen genes have been discovered so far. With two exceptions (selw and selx), superantigens are found on pathogenic islands and prophages. Clinical severity such as sepsis with or without septic shock has been linked to the genomic setup of isolates [17].

Genotypes of clinical strains have been investigated extensively worldwide [18-22]. In contrast, exploration of gene expression and toxin production of clinical isolates is scarce. Transcriptional profiling of superantigens was done in nasal isolates and an outbreak of food poisoning $[23,24]$. Protein production of superantigens was analysed in isolates from patients with atopic dermatitis and diabetic foot ulcers $[16,25]$. In addition, specific production of SEB, SElK and SEH was quantified in clinical isolates [18, 26, 27]. Protein production of alpha toxin was determined in CA-MRSA strains and in isolates from hemodialysis patients [28-30].
Thorough analysis of the production of virulence factors from obtained clinical isolates could help to recognise potencies of bacteria to lyse host cells or hyperstimulate the immune system. In this study, we performed genomic analyses, as well as quantification and functional analyses of secreted toxins from consecutive isolates collected in large hospitals in Vienna and Linz, Austria. Typing of seven house-keeping genes, the spa gene and the agr locus was done to link production rates to possible clusters.

\section{Methods}

\section{Bacterial strains and growth}

Bacterial strains were obtained from the general hospital in Vienna and the general hospital in Linz, Austria. As clinical isolates were anonymous and data of the patients were not accessible, the study was exempt from ethical approval, which was testified by the Ethics Committee of the Immunology Outpatient Clinic (www.itk.at/news) after detailed evaluation of the study protocol. Isolates were identified as $S$. aureus by standard laboratory protocols, grown on tryptic soy broth agar plates. Isolates were not subcultured and thereafter stored at $-80{ }^{\circ} \mathrm{C}$ for further exploration. Bacteremia isolates were designated with the letter B. All strains were identified as MSSA, and genotyped for twenty-four superantigen (-like) genes, four cytolysin genes, the agr groups I-IV, and the spa gene. All primer pairs are listed in Additional file 1: Table S1. None of the primer pairs reacted with our negative control strain Staphylococcus epidermidis ATCC 49461. Genomic DNA templates were purified from overnight cultures according to manufacturer's protocols using the Wizard Purification Kit (Promega). For cell wall disruption cells were treated with lysostaphin and lysozyme (Sigma). DNA was amplified in a T3 thermocycler (Biometra) by 28 cycles of $95{ }^{\circ} \mathrm{C}$ (denaturation) for $30 \mathrm{~s}$, specific annealing temperature for $45 \mathrm{~s}$, and $68{ }^{\circ} \mathrm{C}$ (elongation) for $60 \mathrm{~s}$, using the Platinum Taq PCRx DNA polymerase (Invitrogen). The reaction was initiated by $10 \mathrm{~min}$ incubation at $95{ }^{\circ} \mathrm{C}$, and terminated by $10 \mathrm{~min}$ incubation at $68{ }^{\circ} \mathrm{C}$. Primer sequences and PCR annealing temperatures are shown in Additional file 1: Table S1. Absence of the gene selv was verified through analysis of the genes sei and selm. Distribution statistics were done using the Pearson's chisquared test $\left(\chi^{2}\right)$.

Isolated genomic DNA of all strains was sequenced using the Illumina MiSeq sequencer, the Nextera XT library kit, and the MiSeq reagent kit as instructed by the manufacturer (Illumina). Upon checking the average size of amplicons using the BioAnalyzer (Agilent), and measuring the concentration using the QuBit system (Life technologies), four genomic libraries were combined for sequencing. Reads were mapped to $S$. aureus gene sequences extracted from GenBank (accession numbers: sea NC_003923.1, seb NC_002951.2, sec KF386012.1, sed 
AF053140.1, see M21319.1, tst AB678405.1, seg NC 009782.1, seh NC_002953.3, sei NC_009782.1, selj AF05 3140.1, selk NC_007793.1, sell NC_009782.1, selm NC_0 02745.2, seln EF531605.1, selo CP002388.1, selp NC_00 2745.2, selq NC_017347.1, selr AB330135.1, sels AB33 0135.1, selt AB330135.1, selu AY205307.1, selu2 EF03 0428, selv EF030427, selw CP000046, selx CP007447.1, hla BX571857.1, hlg1 S65052.1, hlg2 S65052.1, agr type I AF2 10055.1, agr type II AF001782.1, agr type III AF001783, agr type IV AF288215.1) using the alignment program CLC (CLCbio, Qiagen). All isolates were sequenced with a minimum coverage of 20 -fold. In order to analyse repeat patterns in spa, de novo assembly of reads was done using CLC [31]. Blastn of contigs against spa (NC002952.2) was performed, and identified gene variants were assigned using the SPATYPEMAPPER software (download at http://www.clondiag.com/fileadmin/Media/Downloads/SP ATypeMapper_0_6.zip). All unknown repeat patterns were re-sequenced (Sanger).

Multilocus sequence typing (MLST) was performed as described in [32]. The seven included genes are $\operatorname{arcC}$, $\operatorname{aroE}$, $g l p F, g m k, p t a, t p i$, and ypiL. Loci information and primer sequences are available on the MLST website, which was also used to analyse all alleles (http://www.mlst.net). New spa type and new MLST type were uploaded to the spa website (http://www.spaserver.ridom.de) and MLST website. Newly identified selx and hla mutations have been deposited at GenBank (accession numbers KT943499 and KU236387).

\section{Protein analysis}

For production of superantigens and hemolysins, strains were cultured to stationary phase $(16 \mathrm{~h})$ in $25 \mathrm{ml}$ of tryptic soy broth at $37{ }^{\circ} \mathrm{C}$ with shaking at 170 revolutions per minute (rpm). Optical densities $\left(\mathrm{OD}_{600}\right)$ of cell cultures were normalised at the beginning of growth (0.02) and compared. In order to receive cell-free supernatants, cultures were centrifuged at $3220 \mathrm{~g}$ for five minutes, followed by a sterile filtration of supernatants (PALL Acrodisc $25 \mathrm{~mm}$ Syringe Filters with $0.2 \mu \mathrm{m}$ Posidyne Membrane) as described before [33]. Filtrates were tested for bacterial growth on agar plates. Samples were stored at $-20{ }^{\circ} \mathrm{C}$.

Upon addition of sample buffer, supernatants were boiled for three minutes. $20 \mu \mathrm{l}$ of each sample were resolved on $15 \%$ SDS-polyacrylamide gels. For Western Blotting, proteins were transferred onto $0.2 \mu \mathrm{m}$ nitrocellulose membranes (GE Healthcare) in a cooled wet blot apparatus (Biorad). Membranes were blocked in a $2 \%$ BSA 1X PBS $0.1 \%$ Tween 20 solution overnight at $4{ }^{\circ} \mathrm{C}$. Antisera used as primary antibodies were employed in a 1:40,000 dilution, secondary antibodies were diluted 1:50,000. Development procedure was performed according to manufacturer's instructions (GE Healthcare).

\section{Expression and purification of proteins}

Recombinant wild type alpha toxin, gamma toxin, SEC, and TSST1 proteins were produced in our lab. Escherichia coli strains (One Shot, Invitrogen) transformed with a pET expression vector (Novagen) carrying hemolysin or superantigen genes, were grown at $28{ }^{\circ} \mathrm{C}$ and protein expression was induced by arabinose for $24 \mathrm{~h}$. Pellets from alpha toxin and TSST1 protein expressing bacteria were resuspended in citrate buffer $(\mathrm{pH} 5)$, sonicated and centrifuged at 47,000 g. Pellets containing one of the two protein components of gamma toxin, HLG1 or HLG2, were resuspended in phosphate buffer ( $\mathrm{pH}$ 6.5). The pellet containing the superantigen SEC was resuspended in citrate buffer ( $\mathrm{pH}$ 5.5). Supernatants were loaded on SPSepharose FF columns (GE Healthcare) and proteins were eluted with a $\mathrm{NaCl}$ gradient. The peak fraction was dialysed with Tris ( $\mathrm{pH} \mathrm{8)}$ and applied to Q-Sepharose FF columns (GE Healthcare). The peak fraction was dialysed against $1 \mathrm{X}$ PBS and samples were stored at $-20{ }^{\circ} \mathrm{C}$.

For the production of antisera, New Zealand White rabbits were purchased from Charles River Laboratories. Animals were kept in standard facilities with free access to water and food (Ssniff), according to the guidelines of the Austrian Ministry for Science and Research. Animal experiments had been approved and controlled by the Veterinary Department of the City of Vienna. Antisera were obtained from rabbits after four rounds of immunisation. Titers were determined through an indirect enzyme-linked immunosorbent assay (ELISA). Flat-bottomed-96-well plates were coated with $0.5 \mu \mathrm{g}$ per well of wild type recombinant alpha toxin or SEC in carbonate buffer $\mathrm{pH} 9.6$ and further prepared as described in the ELISA section. Plates were incubated with $50 \mu \mathrm{l}$ per well of samples for $1 \mathrm{~h}$ at $37{ }^{\circ} \mathrm{C}$. Horseradish peroxidase-conjugated goat anti-rabbit IgG-HRP antibodies (GE Healthcare) were added in a 1:20,000 dilution. Titers of antisera were determined and expressed as the inverse of the highest dilution (done in twofold dilution steps) for valid detection signals. Antiserum raised against wild type alpha toxin had an ELISA titer of 94,445, wild type SEC antiserum contained a binding titer of 112,382. Antiserum raised against wild type TSST1 had a titer of 46,330 and was described previously by Stich et al. [34]. Polyclonal IgGs were precipitated (37 \% ammonium sulfate) from each rabbit antiserum, reconstituted to the initial volume, and stored at $-20{ }^{\circ} \mathrm{C}$ for further use.

\section{Hemolysis assay}

The assay was adapted from $[35,36]$. In detail, a $2 \mathrm{ml}$ sample of blood from rabbits was washed three times with $40 \mathrm{ml}$ of $1 \mathrm{X}$ PBS (610 g, $10 \mathrm{~min})$. Washed rabbit erythrocytes were resuspended in $12 \mathrm{ml} 1 \mathrm{X}$ PBS and verified to have $10^{8}$ cells per $\mathrm{ml}$ using Neubauer counting chambers. The amount of erythrocytes was adjusted 
to give an optical density of 1.5 at $570 \mathrm{~nm}$ (Tecan microplate reader) when added to Saponin (Sigma), which was used as a positive control. Staphylococcal supernatants were used in a final dilution of 1:50. Antisera were employed in 1:50, 1:200, and 1:400 dilutions. Samples consisting of supernatants and antisera were incubated in round-bottomed-96-well plates for $1 \mathrm{~h}$ at $37{ }^{\circ} \mathrm{C}$. Upon addition of rabbit erythrocytes, samples were incubated at $37{ }^{\circ} \mathrm{C}$ for $30 \mathrm{~min}$ and afterwards spun down at $610 \mathrm{~g}$ for $3 \mathrm{~min} .150 \mu \mathrm{l}$ of supernatant were transferred to a new plate, and the optical density of samples was measured at $570 \mathrm{~nm}$ thereafter.

\section{Enzyme-linked immunosorbent assay}

For sandwich enzyme-linked immunosorbent assays (ELISA) monoclonal antibodies were used as capture antibodies, polyclonal antibodies from rabbits were used for detection. In detail, flat-bottomed-96-well plates were coated with $50 \mu \mathrm{l}$ per well of commercially available monoclonal anti-alpha toxin (MAb6D3, BBI Solutions), anti-TSST1 (MAb5T, BioVeris) or anti-SEC (MAb1C3, BioVeris) antibodies in a dilution of 1:3000 (alpha toxin), 1:1000 (TSST1), or 1:2000 (SEC) in carbonate buffer $\mathrm{pH} 9.6$ and stored at $4{ }^{\circ} \mathrm{C}$. After $16 \mathrm{~h}$ of incubation, the plates were washed four times with $1 \mathrm{X}$ PBS pH 7.2 containing $0.1 \%(\mathrm{v} / \mathrm{v})$ Tween-20. Next, wells were blocked with $200 \mu \mathrm{l}$ per well using $1 \mathrm{X}$ PBS containing $2 \%(\mathrm{w} / \mathrm{v})$ BSA and $0.1 \%(\mathrm{v} / \mathrm{v})$ Tween-20, and plates were incubated for $1 \mathrm{~h}$ at room temperature with gentle agitation. Plates were then stored at $-20{ }^{\circ} \mathrm{C}$.

Standards, samples (supernatants) and controls were diluted in blocking buffer and plates were incubated with $100 \mu \mathrm{l}$ per well at room temperature for $90 \mathrm{~min}$ with 150 revolutions per minute. The plates were then washed four times and $100 \mu \mathrm{l}$ per well of polyclonal IgG preparations from rabbit antisera in a dilution of 1:15,000 (alpha toxin) or 1:7500 (TSST1, SEC) in blocking buffer were added. After incubation for $90 \mathrm{~min}$ at room temperature, plates were again washed three times. Goat anti-rabbit IgG-HRP antibodies (GE Healthcare) were added in a 1:5000 dilution $(100 \mu \mathrm{l}$ per well) for $1 \mathrm{~h}$ at room temperature and continuous movement (150 revolutions per minute). An o-phenylendiamine pastille (Sigma) was suspended in substrate buffer. $\mathrm{H}_{2} \mathrm{O}_{2}$ was added to catalyse the reaction, which was kept in the dark at room temperature. To stop this colorimetric reaction, $100 \mu \mathrm{l}$ of a $1 \%(\mathrm{v} / \mathrm{v})$ sulfuric acid solution were added per well. The plates were scanned for absorbance at $492 \mathrm{~nm}$ wavelength (Tecan micro-plate reader).

\section{Results}

Analysis of toxins genes

In this study, the distribution and expression of genes encoding superantigens and hemolysins was explored in
51 fresh clinical and colonisation isolates. 22 strains were derived from patients with bacteremia, 29 isolates were collected from the nasal cavity of healthy individuals. The prevalence of four cytolysin genes and 24 superantigen genes was determined in all strains by singleplex-PCR amplification and whole genome sequencing (Additional file 2: Table S2).

Since both hemolysins, alpha toxin and gamma toxin belong to the core genome, we detected these genes $(h l a, h l g 1, h l g 2)$ in all strains. Despite the fact, that hla was found in all strains by PCR, sequence analysis revealed, that ten isolates (19.6\%) had a known nonsense mutation leading to a shortened alpha toxin protein [37]. The majority of isolates (80.4\%) showed a corrupted beta toxin gene $h l b$, based on the presence of the phage $\phi S a 3$. In contrast, gamma toxin genes hlg1 and $h l g 2$ were present and in frame in all isolates.

The genomic distribution of all known superantigen and superantigen-like genes was further analysed (Additional file 2: Table S2). The latest discovered superantigen-like genes selw and selx were found in 51 isolates $(100 \%)$ and 39 isolates (76.5\%), respectively. Importantly, sequence analysis revealed the lack of a start codon in selw in the vast majority of isolates and only four strains displayed a functional open reading frame of selw (7.8\%). In addition, a yet unknown one base pair deletion has been detected in selx right after the start at position twelve in eight isolates $(15.7 \%)$. The resulting frameshift led to a stop codon in selx at codon position eleven. This means that 20 out of 51 isolates (39.2 \%) did not express SElX due to the corruption or absence of the gene. Further, two strains had a shorter version of selu, which has already been described as selu2 [38].

Genotypic analysis did not reveal a correlation between gene profiles and the source of isolates in this study. Two superantigen encoding genes (tst, selp) were more often found in blood isolates (Fig. 1). However, the difference between blood isolates and colonising isolates was not statistically significant (Table 1). Pseudogene versions of selw were excluded from this analysis. Further, comparison of isolates having no superantigen or superantigen-like genes at all (with the exception of selw and selx), resulted in an even distribution $\left(\mathrm{n}_{\mathrm{b}}=6, \mathrm{n}_{\mathrm{c}}=5\right.$; $P=0.44)$ as well.

To assess clonality of strains, spa typing was performed with all 51 isolates (Table 2). We identified 39 types, among which 30 types were unique (58.8\%). 21 strains were identified to belong to one of nine clusters. The largest cluster comprised four strains (spa type t084), which belonged to the group of isolates without prominent superantigens. One cluster contained three isolates (t091), showing an identical superantigen and cytolysin gene pattern. Six clusters were found to contain only two isolates each (displaying the repeat 


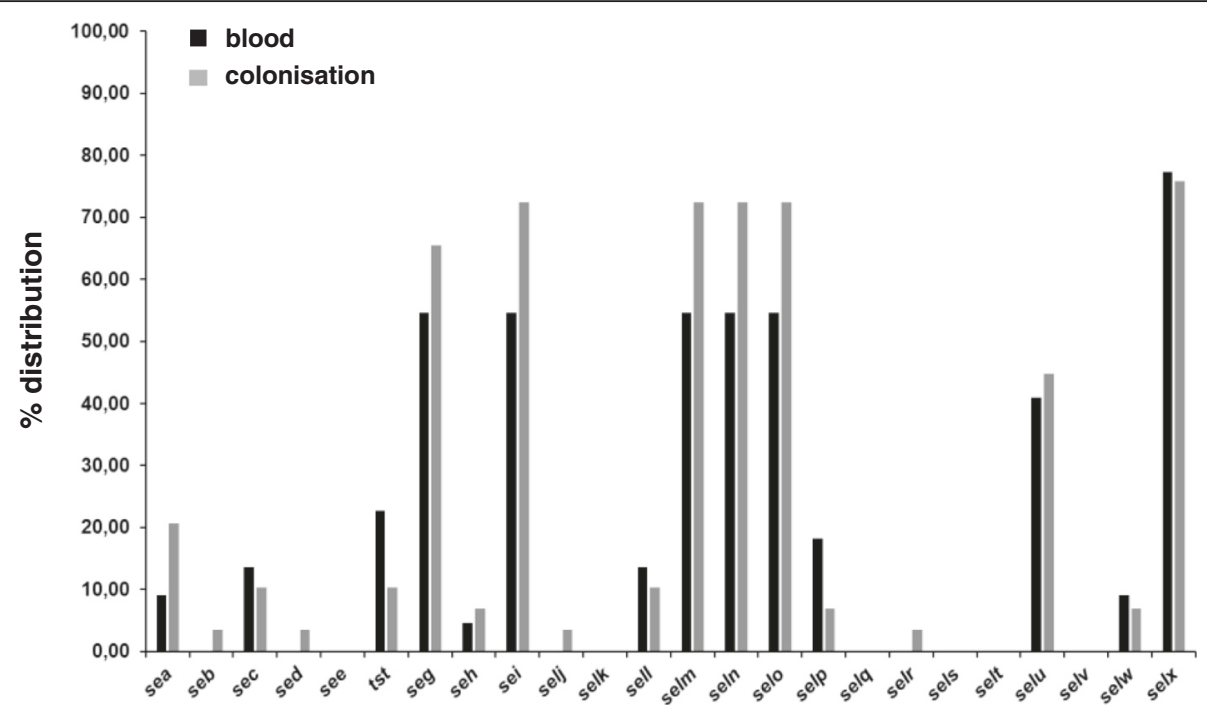

Fig. 1 Prevalence of superantigen and superantigen-like genes in blood isolates and colonisation strains. Percentage of distribution of genes identified by PCR was determined, selw was included when sequencing revealed an ATG start codon

patterns t056, t015, t021, t342, t246, t433). These pairs had identical superantigen and cytolysin gene patterns, however, in one cluster (t056), hlb was found to be corrupted in only one isolate.

Assessment of agr types revealed the presence of all four types in this study (Table 2). Type I was most prevalent $(n=23,45.1 \%)$, whereas type II and III were found in ten $(19.6 \%)$ and thirteen $(25.5 \%)$ isolates, respectively. Type IV was present in five strains (9.8 \%). There was no significant correlation between agr types and isolation site. Strains within each spa type cluster displayed identical agr types. Among the groups of tstpositive and sec-positive strains, only one agr type was predominant: type I was found in all sec-positive isolates, type III was present in seven out of eight tst-positive strains. All other groups defined through superantigen patterns displayed an even distribution of agr types.

Further, MLST was performed to investigate the dispersion of clonal complexes among blood samples and nasal isolates (Table 3). In addition, identified spa types and agr loci were linked to present clonal complexes, and distribution of superantigen and superantigen-like genes was assessed. In total, fourteen clonal complexes were found, with CC30, which comprised twelve isolates, being the most prevalent one. Interestingly, identified valid start codons of selw were restricted to CC5, whereas the nonsense mutation of selx was linked to CC45. MLST of the strain $767 \mathrm{~N}-10$, which displayed spa type t008, revealed a new single locus variant (SLV) of sequence type 8 (ST8), with a different allele of aroE. In far the most cases, identical spa types belong to the same clonal complex. Here, we identified a peculiar deviation, t008 was found in ST8 (B5990) and the newly discovered variant ST3275 (767 N-10). Both STs also differed in their superantigen gene patterns.

\section{Protein expression of bacterial toxins}

Concentrations of alpha toxin, SEC, and TSST1, were determined by ELISA, using commercially available monoclonal antibodies (see Table 2). First, we assessed amounts of alpha toxin in all supernatants grown to stationary phase and compared concentrations of this toxin between distinct groups. Due to the fact that hla was present in all strains, isolates were grouped a priori based on the distribution of superantigens (Table 2, first column). Among the panel of strains bearing no prominent superantigen gene, all supernatants displayed measurable amounts of alpha toxin. Interestingly, we found an up to 500-fold difference in alpha toxin concentration between supernatants. Two strains produced significantly higher amounts: Rv53944 $(25.4 \mu \mathrm{g} / \mathrm{ml})$ and B7715 (11.45 $\mu \mathrm{g} / \mathrm{ml}) .0 .05 \mu \mathrm{g} / \mathrm{ml}$ was the lowest amount of alpha toxin found in the supernatants of two blood isolates (B5990 and B50188).

Within the group of sec-positive strains, the divergence between secreted alpha toxin amounts was less pronounced. However, the supernatant with the highest amount of alpha toxin produced, belonged to this group: B958 with $36.1 \mu \mathrm{g} / \mathrm{ml}$. Among the group of tst-positive strains, we found seven strains bearing the nonsense mutation in hla $(7 / 8,87.5 \%)$. In these strains, concentration of alpha toxin was below the detection limit of $0.01 \mu \mathrm{g} / \mathrm{ml}$. The only isolate with a functional alpha toxin among these strains (B2284, sole agr type II) showed an amount of $0.99 \mu \mathrm{g} / \mathrm{ml}$. Characterisation of strains from the two remaining groups of egc strains and 
Table 1 Prevalence of superantigen and superantigen-like open reading frames in blood and colonising isolates

\begin{tabular}{|c|c|c|c|c|}
\hline & All $(n=51)^{a}$ & Blood $(n=22)^{a}$ & Colonising $(n=29)^{a}$ & $P$-value ${ }^{b}$ \\
\hline sea & $8(15.7)$ & $2(9.1)$ & $6(20.7)$ & 0.26 \\
\hline seb & $1(1.9)$ & $0(0)$ & $1(3.4)$ & nd \\
\hline $\sec$ & $6(11.8)$ & $3(13.6)$ & $3(10.3)$ & 0.72 \\
\hline sed & $1(1.9)$ & $0(0)$ & $1(3.4)$ & nd \\
\hline see & - & - & - & \\
\hline tst & $8(15.7)$ & $5(22.7)$ & $3(10.3)$ & 0.23 \\
\hline seg & $31(60.8)$ & $12(54.5)$ & $19(65.5)$ & 0.43 \\
\hline seh & $3(5.9)$ & $1(4.5)$ & $2(6.9)$ & 0.72 \\
\hline sei & $33(64.7)$ & $12(54.5)$ & $21(72.4)$ & 0.19 \\
\hline selj & $1(1.9)$ & $0(0)$ & $1(3.4)$ & nd \\
\hline selk & - & - & - & \\
\hline sell & $6(11.8)$ & $3(13.6)$ & $3(10.3)$ & 0.72 \\
\hline selm & $33(64.7)$ & $12(54.5)$ & $21(72.4)$ & 0.19 \\
\hline seln & $33(64.7)$ & $12(54.5)$ & $21(72.4)$ & 0.19 \\
\hline selo & $33(64.7)$ & $12(54.5)$ & $21(72.4)$ & 0.19 \\
\hline selp & $6(11.8)$ & $4(18.2)$ & $2(6.9)$ & 0.22 \\
\hline selq & - & - & - & \\
\hline selr & $1(1.9)$ & $0(0)$ & $1(3.4)$ & nd \\
\hline sels & - & - & - & \\
\hline selt & - & - & - & \\
\hline seluc & $21(41.2)$ & $8(36.4)$ & $13(44.8)$ & 0.54 \\
\hline selv & - & - & - & \\
\hline selw ${ }^{d}$ & $4(7.8)$ & $2(9.1)$ & $2(6.9)$ & 0.77 \\
\hline selx & 39 (76.4) & $17(77.3)$ & $22(75.8)$ & 0.91 \\
\hline
\end{tabular}

${ }^{\mathrm{a}} \mathrm{No}$. of PCR-amplified and sequenced genes, percentages are in parentheses bPearson's chi-squared test $\left(x^{2}\right)$ performed for distribution of in-frame genes $(n>1)$

'selu and selu2 combined as selu

${ }^{\mathrm{s}}$ selw with identified ATG as start codon

variant strains revealed similar, wide-ranging alpha toxin concentrations.

Thereafter, we determined the amount of secreted SEC and TSST1 (Table 2). Analysis of the respective protein production revealed a broad range of production rates. All six strains bearing sec were able to produce significant amounts of SEC. However, there was a ten-fold difference between the highest $(19.71 \mu \mathrm{g} / \mathrm{ml})$ and lowest $(1.95 \mu \mathrm{g} / \mathrm{ml})$ amount measured. We also found varying TSST1 concentrations among tst-positive strains. Six out of eight samples showed one-digit $\mu \mathrm{g}$ values. Two strains stepped out of the line: the nasal isolates Rv52959 and Rv54054, which were both identified to carry the intact tst gene, produced only minimal amounts of TSST1 $(0.06 \mu \mathrm{g} / \mathrm{ml}$ and $0.01 \mu \mathrm{g} / \mathrm{ml}$, respectively).

Comparison of production rates and agr types did not unravel the broad range of concentrations of superantigens or alpha toxin. Of note, among the small group of agr type IV strains, all produced alpha toxin in $\mu \mathrm{g}$ ranges. All isolates bearing the hla mutation were found to have agr type III. In contrast, comparison of alpha toxin production rates revealed noteworthy differences between clonal complexes (see Table 3, last column). We found clonal complexes with rates around $1 \mu \mathrm{g}$ per $\mathrm{ml}$ (CC5, ST7), clonal complexes displaying much higher average amounts (CC8, CC22, CC45), and clonal complexes showing much lower amounts (CC15, and CC30). However, sample sizes between clonal complexes differed considerably. Strikingly, spa typing of isolates revealed a high similarity of production rates among identical spa types and exotoxin gene patterns (Table 4). These similarities within spa type clusters were found throughout all clonal complexes. The two members of the sec-positive cluster produced almost identical quantities of SEC, the two pairs of tst-positive isolates showed highly similar amounts of TSST1 in their supernatants. In addition, within the eight spa typing clusters, quantification of alpha toxin revealed related amounts.

\section{Functional assessment of hemolysis}

Alpha toxin quantification confirmed the expression of hla in the majority of strains. Assessment of functional activity of alpha toxin in all supernatants to lyse freshly prepared rabbit erythrocytes revealed hemolytic activities in corresponding strains (data not shown). However, surprisingly, all tst-positive isolates having the hla nonsense mutation displayed hemolysis. Therefore, based on varying alpha toxin production rates, we chose to compare hemolysis of strains within three major, homogeneous groups of isolates defined through distinct superantigen and cytolytic gene patterns. Strains identified as tst-positive showed no alpha toxin production (with one exception), sec-positive isolates displayed high amounts of alpha toxin in their supernatants, whereas strains without prominent superantigens showed a very broad variation of production (see Table 2). Strains were divided into three sets i) having no superantigens $(n=11)$, ii) having $\sec (n=6)$, and iii) having tst $(n=8)$ (Fig. 2a). Within the first group, all supernatants displayed hemolysis. The two blood isolates that showed the lowest alpha toxin production (B5990, B50188), also showed the weakest hemolysis. All supernatants of the sec-positive strains showed hemolytic activity as well. Surprisingly, in the group of tst-positive isolates, five supernatants displayed hemolysis despite the absence of full-length alpha toxin. Only two tst-positive colonising samples (Rv52959, Rv54054) showed no hemolysis.

We explored the reason for the hemolytic activity of all tst-positive strains lacking functional hla in more detail. Beside alpha toxin, pore-forming gamma toxin lyses blood cells as well. To assess the putative presence of gamma toxin in the tst-positive samples, we 
Table 2 Results for testing the presence of superantigens, cytolysins and the measurement of protein amounts in hospital-derived isolates

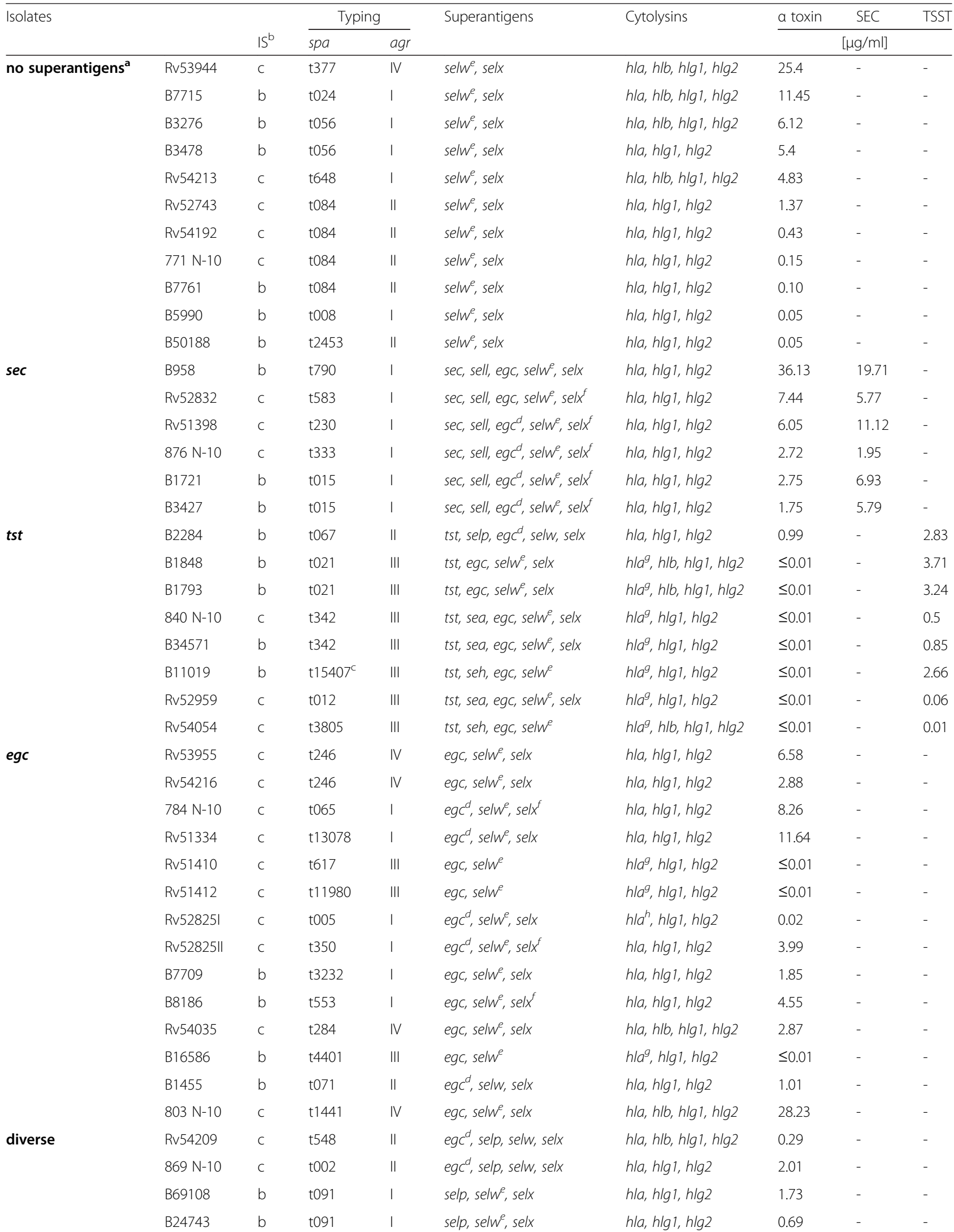


Table 2 Results for testing the presence of superantigens, cytolysins and the measurement of protein amounts in hospital-derived isolates (Continued)

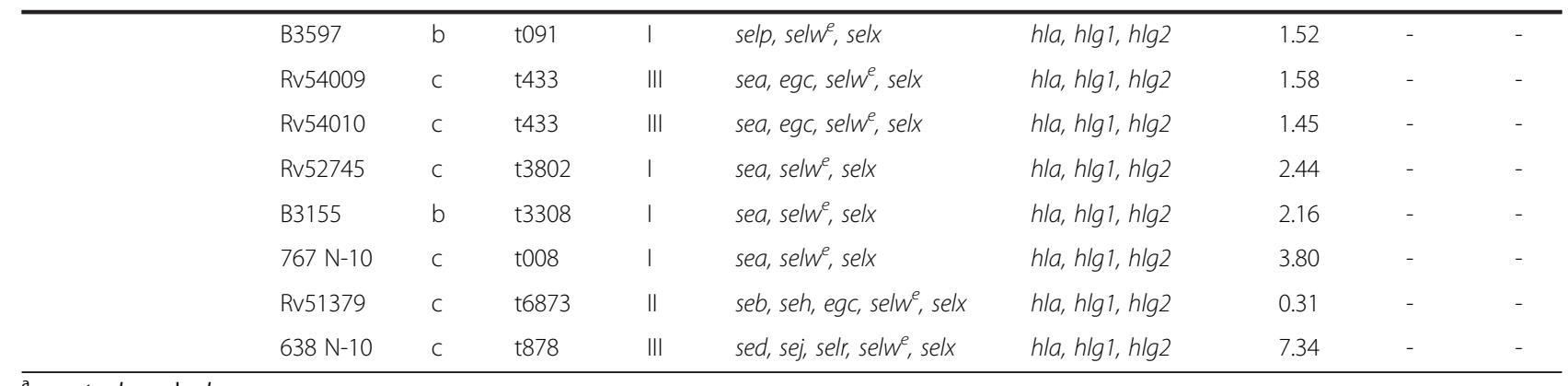

\section{aexcept selw and selx}

b Isolation Site including (b) blood isolates and (c) colonising strains

'new, unique repeat pattern 04-54-31-12-16-34-16-12-25

${ }^{d}$ no selu

edue to the absence of the atg start codon designated as pseudogene

${ }^{f}$ frameshift nonsense mutation in selx (I11)

${ }^{9}$ nonsense mutation in hla (Q113)

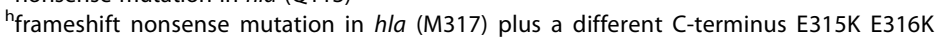

performed western blotting with all tst-positive strains for HLG1, one essential monomer of gamma toxin (Fig. 2b). Despite a high background level due to the Fc binding capacity of certain S. aureus supernatants, five isolates which had displayed hemolysis before, were positive for HLG1. The two colonising isolates (Rv52959 and Rv54054), which did not perform any hemolysis at all, did not show HLG1 protein. Thereafter, we determined activity of recombinant wild type alpha toxin and recombinant wild type gamma toxin (Fig. 2a right panel). We were able to detect hemolysis at toxin concentrations as low as 10 ng per well.

Then we selectively blocked hemolysis of supernatants in this assay by applying alpha toxin and gamma toxin

Table 3 Characterisation of clonal complexes and comparison of alpha toxin production rates

\begin{tabular}{|c|c|c|c|c|c|}
\hline Clonal complex & $\mathrm{ST}(\mathrm{n})$ & spa (n) & $\operatorname{agr}(\mathrm{n})$ & Superantigens ${ }^{\mathrm{b}}$ & Production $(\mathrm{m} / \mathrm{sd})^{d}$ a toxin \\
\hline \multirow{2}{*}{ CC5 } & ST5 (3) & t071, t548, t002 & II (3) & selp (2), egc (3), selw (3), selx (3) & \multirow[t]{3}{*}{$1.1(+/-0.7)$} \\
\hline & ST1457 (1) & t067 & $\|$ & tst, selp, egc, selw, selx & \\
\hline cC6 & ST6 (1) & t3802 & I & sea, selx & \\
\hline \multirow[t]{2}{*}{ ST7 } & ST7 (3) & t091 (3) & I (3) & selp (3), selx (3) & \multirow[t]{2}{*}{$1.32(+/-0.55)$} \\
\hline & ST8 (4) & t3308, t024, t008, t648 & \multirow{2}{*}{ I (5) } & sea (1), selx (4) & \\
\hline \multirow[t]{2}{*}{ CC8 } & ST3275 $(1)^{\mathrm{a}}$ & t008 & & sea (1), selx (1) & \multirow[t]{2}{*}{$8.78(+/-10.23)$} \\
\hline & ST630 (1) & t377 & IV & selx & \\
\hline CC10 & ST10 (1) & t6873 & $\|$ & seb, seh, egc, selx & \\
\hline \multirow{2}{*}{ CC15 } & ST15 (2) & t2453, t084 & \multirow{2}{*}{ ॥ (5) } & $\operatorname{selx}(2)$ & \multirow{2}{*}{$0.42(+/-0.55)$} \\
\hline & ST582 (3) & t084 (3) & & selx (3) & \\
\hline CC22 & ST22 (3) & t790, t13078, t005 & I (3) & $\sec (1), \operatorname{sell}(1), \operatorname{egc}(3), \operatorname{sel}(3)$ & $15.93(+/-18.43)$ \\
\hline CC25 & ST25 (1) & t3232 & । & egc, selx & \\
\hline \multirow{2}{*}{ CC30 } & ST30 (10) & t433 (2), t4401, t11980, t617, t012, t021 (2), t342 (2) & III (10) & tst (5), sea (5), egc (10), selx (10) & \multirow{2}{*}{$\leq 0.01$} \\
\hline & ST34 (2) & t3805, t15407 & III (2) & tst (2), seh (2), egc (2), selx (2) & \\
\hline CC45 & ST45 (8) & t015 (2), t333, t230, t583, t065, t350, t553 & I (8) & $\sec (5)$, sell (5), egc (8), selx (8) ${ }^{c}$ & $4.69(+/-2.36)$ \\
\hline CC50 & ST50 (2) & t246 (2) & IV (2) & egc (2), selx (2) & \\
\hline CC51 & ST121 (2) & $\mathrm{t} 284, \mathrm{t} 1441$ & IV (2) & egc (2), selx (2) & \\
\hline CC101 & ST101 (2) & t056 (2) & I (2) & selx (2) & \\
\hline CC779 & ST779 (1) & t878 & III & sed, sej, selr, selx & \\
\hline
\end{tabular}

${ }^{a}$ Strain $767 \mathrm{~N}-10$ displayed a different allele of aroE, being a new single locus variant of ST8

${ }^{\mathrm{b}}$ All superantigen genes were included with the exception of pseudogenes

'Superantigen-like gene selx including frameshift nonsense mutation (I11)

${ }^{\mathrm{d}}$ Mean $(\mathrm{m})$ and standard deviation (sd) of production rates were determined of CC groups comprising one or more STs (number of strains $\mathrm{n} \geq 3$ ) 
Table 4 Comparison of protein amounts in spa typing clusters with identical superantigen and alpha toxin gene patterns of hospital-derived isolates

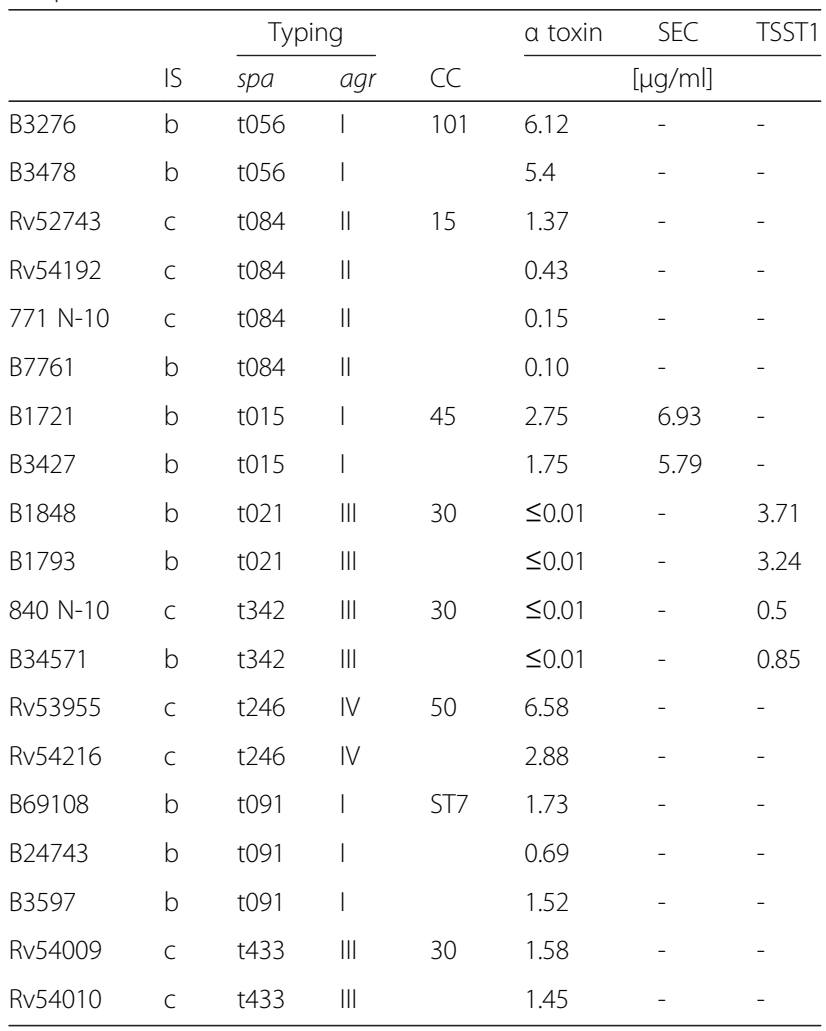

antisera from rabbits immunised with recombinant proteins (Table 5). Both antisera blocked only hemolysis of the specific hemolysin, thereby reaching neutralisation levels of 95 \% (Fig. 2c). In the first group (upper panel), supernatants had to be neutralised by antisera against both, alpha toxin and gamma toxin, while other supernatants could be neutralised with antiserum against alpha toxin alone. Interestingly, the two isolates of one spa type cluster, which also differed in the presence of the intact $h l b$ gene, differed in the neutralisation patterns of hemolysis: the supernatant of B3478 had to be neutralised with both antisera, whereas the supernatant of B3276 was neutralised with antiserum against alpha toxin alone. In the sec-positive group, it was necessary to apply both antisera, indicating that all supernatants contained both, alpha toxin and gamma toxin. In the group consisting of tst-positive strains, supernatants of five strains lacking full length alpha toxin were neutralised by gamma toxin antiserum alone, while the remaining supernatant (B2284) was neutralised by alpha toxin alone. This underlined the extraordinary potency of both, alpha and gamma toxin, to harm cells of the host.

\section{Discussion}

Comprehensive studies of genotypes and phenotypes of clinical S. aureus isolates are scarce. To contrast differences between SAB isolates and colonising strains, we performed MLST, spa and agr typing, we determined the presence of four hemolysin genes and 24 superantigen genes in 22 blood and 29 colonising isolates, and thereafter compared production of alpha toxin, and the two prominent superantigens, TSST1 and SEC. Allocation of genes and production rates of exotoxins was equally distributed between blood and colonising samples. However, corrupted genes and production patterns were linked to certain clonal complexes. Spa typing was found to be a suitable predictor for highly similar toxin production rates.

The prevalence of genes encoding superantigens or superantigen-like proteins was both abundant and diverse among blood and nasal isolates. In 2004, a German multicenter study including 429 isolates from 32 hospitals revealed $73 \%$ of all samples studied to be SE positive [19]. Among 51 isolates, we found $78 \%$ to carry common superantigen genes. In accordance with the majority of previous reports, we did not see any correlation between superantigen distribution and isolation site $[18,19]$. We assume that the presence or absence of superantigens and cytolysins does not decide about the success of colonisation. In this line, subsequent bacteremia is likely to be more dependent on host factors than the arsenal of exotoxins [39]. Still, we cannot exclude that these virulence factors can facilitate invasion at specific entry sites. The severity of disease upon invasion such as pneumonia or endocarditis has been shown to be effected by the presence of prominent superantigens in rabbit models $[40,41]$.

All tested isolates contained at least two staphylococcal enterotoxin-like genes, since both, selw and selx were found in all strains, even those lacking any other superantigen. Selw was identified in all strains, whereas selx was found in $76.5 \%$ of isolates. Importantly, we found that more than $90 \%$ of isolates had no corresponding start codon at the correct position in selw, questioning its relevance as a putative virulence factor. However, we could not exclude the use of alternative codons as transcription start site. The exact role of SElW remains to be determined [42]. Interestingly, selx was found to be mutated in seven isolates. Thus functional SElX was lacking in $39.2 \%$ of all isolated strains. Wilson and colleagues discovered selx in $95 \%$ of 114 tested isolates [43]. To our knowledge, our study was the first to include both, selw and selx, in genotypic analysis of clinical and colonisation isolates.

Agr typing revealed the presence of all four types. Homogeneous distribution was found in sec-positive isolates (type I), and in tst-positive isolates (type III), as 

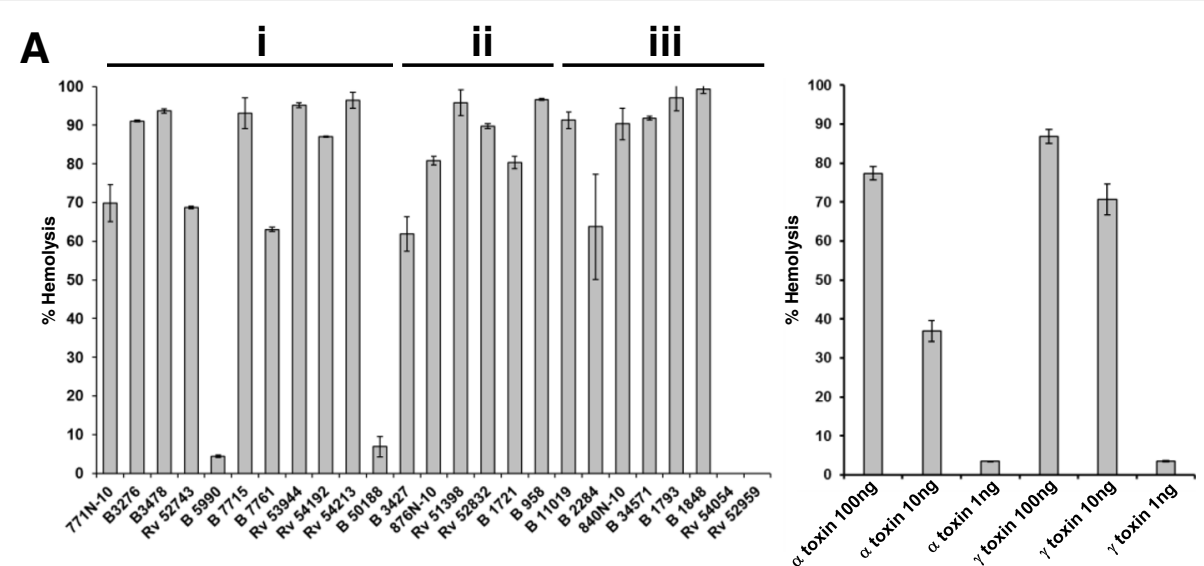

B

\section{HLG1}

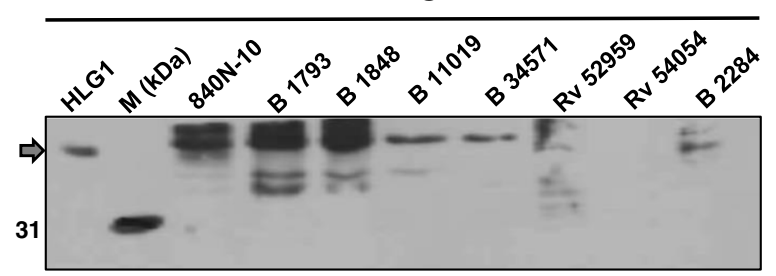

C

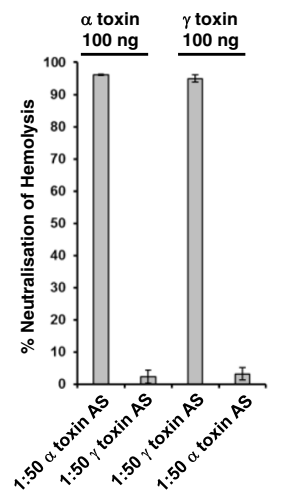

Fig. 2 Hemolysis of erythrocytes through supernatants from S. aureus depends on alpha toxin and gamma toxin. a To measure percentage of hemolysis, cells were grown to stationary phase, and sterile-filtered supernatants were diluted 1:50 in 1X PBS. Absolute hemolysis was defined as the optical density of freed heme upon the addition of the natural glycoside saponin (from Quillaja saponaria) and was set at 100\%. Each run of hemolysis was accompanied by parallel measurement of saponin as positive control and 1X PBS as negative control. Percentages were calculated from mean values out of three independent experiments. Groups i) to iii) are defined in the text. Recombinant wild type alpha toxin and recombinant wild type gamma toxin were diluted in 1 X PBS to receive 100 ng, 10 ng, and 1 ng per well. For neutralisation, 100 ng of toxin was incubated with or without 50-fold diluted antisera (AS) in parallel for $1 \mathrm{~h}$ at $37^{\circ} \mathrm{C}$. b Western blot analysis of HLG1 protein levels in the supernatants of tst-positive isolates. $20 \mu \mathrm{l}$ were taken from each supernatant (sn) and loaded undiluted. $0.1 \mu \mathrm{g} / \mu \mathrm{l}$ of recombinant wild type HLG1 was used as positive control (lane 1, grey arrow). Broad range standard (Biorad) was added to identify correct bands (lane 2). Upon blotting, membrane was cut to avoid extensive background. c Neutralisation of hemolysis of erythrocytes through antisera was assessed. To verify specificity, antiserum against alpha toxin or gamma toxin was used as control for the opposite hemolysin (100 ng per well). Antisera were applied in a final 50-fold dilution and incubated for $1 \mathrm{~h}$ at $37{ }^{\circ} \mathrm{C}$. Hemolysis and percentage calculation (here for neutralisation of hemolysis) was done as described in (a)

previously reported [44]. All agr types were equally distributed in the remaining isolates. Spa typing uncovered 30 unique strains whereas the minority of strains were linked to small clusters. Epidemiological data from contact tracing information were not available. Genotypic information of isolates clustered by MLST and spa typing was identical, with one exception. The disruption of $h l b$ was reversed in the second isolate of the paired cluster with the spa repeat pattern t056. Phage excision resulting in reintroduction of beta toxin production has already been shown [45].

Differences in hemolytic activity regarding TSS isolates were already reported in 1982 [46, 47]. The involvement of alpha toxin was shown a few years later $[48,49]$, the specific nonsense stop mutation also detected in our strains was described in 1990 [37]. In our study, highly variable expression rates of alpha toxin could be detected in both blood and colonising isolates. In fact, alpha toxin production by individual blood strains varied up to 700 -fold. This might be due to variations in the concentration of the regulator RNAIII, or the lack of host cell stimulators [50]. In our study, analysis of agr typing revealed that all strains having the hla mutation belonged to agr type III. Low producers were also found in agr types I and II. Remarkably, $20 \%$ of all strains produced less that $1 \mu \mathrm{g}$ per $\mathrm{ml}$ of alpha toxin. Analysis of the $\operatorname{agrC}$ sequence of the two isolates producing less than $0.1 \mu \mathrm{g}$ per $\mathrm{ml}$ (B5990, B50188) did not reveal the already described $a g r C_{\mathrm{G} 55 \mathrm{R}}$ single nucleotide polymorphism [51]. Small spa clusters were found among alpha toxin high and low producers, and isolates having the hla mutation. Spaulding and colleagues hypothesised 
Table 5 Analysis of hemolytic performance of hemolysins upon neutralisation in hospital-derived isolates

\begin{tabular}{|c|c|c|c|c|c|}
\hline \multirow[t]{2}{*}{ Isolates } & & \multirow[t]{2}{*}{ Cytolysins } & \multicolumn{3}{|c|}{$>90 \%$ Inhibition of hemolysis } \\
\hline & & & $\bar{a}$ toxin $\mathrm{AS}^{\mathrm{c}}$ & $\gamma$ toxin $\mathrm{AS}^{\mathrm{C}}$ & $a / y$ toxin $A S^{c}$ \\
\hline \multirow[t]{11}{*}{ no superantigens ${ }^{a}$} & Rv53944 & hla, hlb, hlg1, hlg2 & & & $1: 50 / 1: 200$ \\
\hline & B7715 & hla, hlb, hlg1, hlg2 & & & $1: 100 / 1: 200$ \\
\hline & B3478 & $h l a, h \lg 1, h \lg 2$ & & & $1: 400 / 1: 400$ \\
\hline & Rv54213 & $h l a, h l b, h \lg 1, h \lg 2$ & & & $1: 400 / 1: 200$ \\
\hline & Rv54192 & hla, hlg1, hlg2 & & & $1: 400 / 1: 400$ \\
\hline & B3276 & $h l a, h / b, h \lg 1, h \lg 2$ & $1: 400$ & & \\
\hline & Rv52743 & hla, hlg1, hlg2 & $1: 400$ & & \\
\hline & B50188 & hla, hlg1, hlg2 & $1: 400$ & & \\
\hline & $771 \mathrm{~N}-10$ & $h \operatorname{la}, h \lg 1, h \lg 2$ & $1: 400$ & & \\
\hline & B5990 & hla, hlg1, hlg2 & $1: 400$ & & \\
\hline & B7761 & hla, hlg1, hlg2 & $1: 400$ & & \\
\hline \multirow[t]{6}{*}{ sec } & B958 & hla, hlg1, hlg2 & & & $1: 50 / 1: 400$ \\
\hline & Rv52832 & hla, hlg1, hlg2 & & & $1: 400 / 1: 200$ \\
\hline & Rv51398 & hla, hlg1, hlg2 & & & $1: 400 / 1: 200$ \\
\hline & B1721 & hla, hlg1, hlg2 & & & $1: 400 / 1: 400$ \\
\hline & $876 \mathrm{~N}-10$ & $h \operatorname{la}, h \lg 1, h \lg 2$ & & & $1: 400 / 1: 400$ \\
\hline & B3427 & hla, hlg1, hlg2 & & & $1: 400 / 1: 400$ \\
\hline \multirow[t]{8}{*}{ tst } & B2284 & hla, hlg1, hlg2 & $1: 400$ & & \\
\hline & B11019 & $h l a^{b}, h \lg 1, h \lg 2$ & & $1: 200$ & \\
\hline & $840 N-10$ & $h l^{b}, h \lg 1, h \lg 2$ & & $1: 400$ & \\
\hline & B34571 & $h l^{b}, h \lg 1, h \lg 2$ & & $1: 200$ & \\
\hline & B1848 & $h l a^{b}, h / b, h \lg 1, h \lg 2$ & & $1: 200$ & \\
\hline & B1793 & $h l a^{b}, h l b, h \lg 1, h \lg 2$ & & $1: 200$ & \\
\hline & Rv52959 & $h l^{b}, h \lg 1, h \lg 2$ & - & - & - \\
\hline & Rv54054 & $h / a^{b}, h / b, h \lg 1, h \lg 2$ & - & - & - \\
\hline
\end{tabular}

a except selw and selx

bonsense mutation in hla (Q113)

${ }^{\mathrm{C}} A S$ antiserum

that the reduction of alpha toxin production in USA200 strains facilitates colonisation of mucosal surfaces [2]. In a recent publication, Sharma-Kuinkel et al. describe that the absence of functional alpha toxin was associated with a negative clinical outcome, indicating the clinical relevance of other virulence factors [30]. In their study, $14.5 \%$ of 200 tested strains showed no alpha toxin production. Here, we found that $19.6 \%$ of all isolates lacked alpha toxin production.

Overall, high-level alpha toxin secretion does not seem to be mandatory for the colonisation of the human host by $S$. aureus, since strains lacking hla expression are continuously isolated from patients. Long-term persistence might be easier to achieve through the decrease of the overall burden caused by secreted exotoxins. Compromised body defence mechanisms could be a major reason for those strains to enter the bloodstream and organs. It was already reported before that CC30 isolates, which are often associated with severe infection, accumulate the hla nonsense mutation [51]. In our study, CC30 tst-positive clones displayed complete absence of functional Hla. Amounts of alpha toxin varied between the identified clonal complexes with $\mathrm{CC} 22$ displaying the highest yield of Hla. CC22 was found to be associated with osteoarticular infections but was negatively associated with persistent bacteremia [39, 52]. Further quantifications of exotoxins are needed to confirm their relevance for persistence, invasion and severity of disease. It remains to be clarified whether in vitro toxin production rates reflect the situation in the host. Comparison of alpha toxin production in vitro and in an infective endocarditis model in rabbit revealed the production of significant amounts in both settings [53].

Alpha toxin is still thought to be one of the most important candidates of $S$. aureus for vaccine development, clinical studies test monoclonal antibodies against alpha 
toxin as primary targets for treatment. However, the role of gamma toxin should not be underestimated, our results suggest that gamma toxin is of importance for toxicity in the absence of hla expression. Alpha toxin and gamma toxin act at least partly on the same target cells $[13,54]$. It was shown that both promote virulence in a murine model [55]. Both, alpha toxin and gamma toxin were found to activate caspase- 1 in the presence of bacterial lipoprotein, ultimately leading to necrotic cell death [56]. Synergy of alpha toxin and gamma toxin could facilitate survival in the host. In our study, the necessity to neutralise both alpha toxin and gamma toxin, to block hemolysis in $44 \%$ of all tested isolates, demonstrated this functional redundancy. The specific role of gamma toxin for the lysis of human erythrocytes was just recently shown by Spaan et al. [57].

Availability of both monoclonal antibodies and polyclonal antisera allowed us to further characterise TSST1 and SEC. Blood isolates and colonising isolates contained high and low producers. We did not see a concordance between production rates of superantigens and production rates of alpha toxin. Varshney et al. determined the expression rate of $s e b$ in $S$. aureus isolates [18]. They also found that SEB production varied greatly among individual strains grown under identical conditions. When we compared expression rates of SEC within the genetically homogeneous $s e c$-positive group, we found an up to 10-fold difference. Among the eight tst-positive isolates, we found four distinct superantigen patterns. Accordingly, results of these strains varied even more. Nevertheless, weak expression of superantigens may still be a potential threat for host cells [58]. Beside the lack of genotypic differences between colonising strains and blood isolates, production rates of superantigens did not distinguish between them either. For example, the two $\mathrm{sec} / \mathrm{sell}$ strains with the highest production rates of SEC displayed identical complex gene patterns (with the exception of selu2), but were isolated from both, the nasal cavity and blood. We suggest that fatality of superantigens comes into play when $S$. aureus manages to enter the bloodstream and organs [59].

Importantly, in both groups, SAB and colonisation, the small clusters based on spa typing displayed similar production rates. Even though not surprising, this correlation of spa types and specific production rates has not been shown before. In contrast, identical complex gene patterns, including both superantigen encoding genes located on various insertion sites and cytolysin encoding genes belonging to the core genome, gave no information about expectable production rates of the tested exotoxins. Despite being a single-locus typing technique, analysis of the polymorphic repeats within the spa gene gave a sufficient resolution to identify clusters of high or low producers of specific toxins. Thus, identical virulence gene patterns could not predict production rates, but spa typing was suitable for correct predictions, regardless of the isolation site.

\section{Conclusions}

Quantitative and functional characterisation of toxins supports the understanding of clinical relevance. In this study, we compared distribution and secretion of $S$. aureus exotoxins of fresh isolates. Genotypic analysis revealed that all superantigen genes were in frame with the exception of the two new superantigen genes located in the core genome, selw and selx, showing unexpectedly high corruption rates, which were linked to specific clonal complexes. Identical genotypic characteristics did not allow a quantitative prediction for secretion. Essentially, we discovered that strains within each of the spa typing clusters produced highly similar amounts of the respective toxins in supernatants. Despite a broad range, we found that clonal complexes displayed distinct alpha toxin production rates. A high prevalence of both the hla nonsense mutation and tst was found in CC30. Phenotypic analysis showed that both, alpha toxin and gamma toxin participated, albeit to different degrees, in the hemolytic activity detected in culture supernatants. In addition to genotypic characterisation, we consider further quantification of varying toxin productions in bacterial populations to be clinically important for the development of efficient treatments.

\section{Availability of supporting data}

Supporting data provided as additional files include all primer sequences and annealing temperatures for superantigen and hemolysin gene singleton PCR. Further, an overview table with all according identified genes is provided. Newly identified mutations are available at the GenBank database (accession numbers KT943499 and KU236387). New spa types and MLST types were uploaded to the spa website (http://www.spaserver.ri dom.de) and MLST website (http://www.mlst.net) and are freely accessible.

\section{Additional files}

Additional file 1: Table S1. Primer Sequences and Annealing Temperatures. (PDF $357 \mathrm{~kb}$ )

Additional file 2: Table S2. Genomic Setup of Superantigens and Cytolysins of 51 clinical isolates. (PDF $460 \mathrm{~kb}$ )

\section{Abbreviations}

CA-MRSA: Community-acquired methicillin-resistant Staphylococcus aureus; HLA: Hemolysin alpha; SAB: Staphylococcus aureus bacteremia; MSSA: Methicillin-sensitive Staphylococcus aureus; MLST: Multi locus sequence typing; SE: Staphylococcal enterotoxin; SEl: Staphylococcal enterotoxin-like; SLV: Single locus variant; TSS: Toxic shock syndrome; TSST1: Toxic shock syndrome toxin 1. 


\section{Competing interests}

The authors declare that they have no competing interests.

\section{Authors' contributions}

$A R, H M W$, and MME designed the experiments and wrote the manuscript. $\mathrm{GH}$ and JB performed expression and purification of proteins, $\mathrm{AR}, \mathrm{GH}$, and CBG contributed to sample preparation and sequencing. $A R, C G$, and NM contributed to protein quantification and animal tests. All authors read and approved the final draft of the manuscript.

\section{Acknowledgements}

We want to thank Prof. Dr. Alexander Hirschl, Head of Department of Clinical Microbiology at the General Hospital in Vienna, and Prim. Dr. Christian Gabriel, Head of Blutzentrale Linz, for providing us with S. aureus strains. Further we would like to thank Susanne Riss for collecting isolates.

This work was supported by the Austrian Research Promotion Agency FFG grants 839130 and 844049

Received: 7 September 2015 Accepted: 22 January 2016 Published online: 01 February 2016

\section{References}

1. Gagliotti C, Balode A, Baquero F, Degener J, Grundmann H, Gür D, et al. Escherichia coli and Staphylococcus aureus: bad news and good news from the European Antimicrobial Resistance Surveillance Network (EARS-Net, formerly EARSS), 2002 to 2009. Euro Surveill Bull Eur Sur Mal Transm Eur Commun Dis Bull. 2011;16(11).

2. Spaulding AR, Salgado-Pabón W, Kohler PL, Horswill AR, Leung DYM, Schlievert PM. Staphylococcal and streptococcal superantigen exotoxins. Clin Microbiol Rev. 2013;26:422-47.

3. Otter JA, French GL. Molecular epidemiology of community-associated meticillin-resistant Staphylococcus aureus in Europe. Lancet Infect Dis. 2010; 10:227-39.

4. WHO - Antimicrobial resistance: global report on surveillance 2014 [http://www.who.int/drugresistance/documents/surveillancereport/en/]

5. DeVries AS, Lesher L, Schlievert PM, Rogers T, Villaume LG, Danila R, et al. Staphylococcal toxic shock syndrome 2000-2006: epidemiology, clinical features, and molecular characteristics. PLoS One. 2011;6:e22997.

6. Peacock SJ, Moore CE, Justice A, Kantzanou M, Story L, Mackie K, et al. Virulent combinations of adhesin and toxin genes in natural populations of Staphylococcus aureus. Infect Immun. 2002;70:4987-96.

7. Chavakis T, Preissner KT, Herrmann M. The anti-inflammatory activities of Staphylococcus aureus. Trends Immunol. 2007;28:408-18.

8. Foster TJ, Geoghegan JA, Ganesh VK, Höök M. Adhesion, invasion and evasion: the many functions of the surface proteins of Staphylococcus aureus. Nat Rev Microbiol. 2014;12:49-62.

9. Feng Y, Chen C-J, Su L-H, Hu S, Yu J, Chiu C-H. Evolution and pathogenesis of Staphylococcus aureus: lessons learned from genotyping and comparative genomics. FEMS Microbiol Rev. 2008;32:23-37.

10. Lindsay JA, Ruzin A, Ross HF, Kurepina N, Novick RP. The gene for toxic shock toxin is carried by a family of mobile pathogenicity islands in Staphylococcus aureus. Mol Microbiol. 1998;29:527-43.

11. Novick RP, Schlievert P, Ruzin A. Pathogenicity and resistance islands of staphylococci. Microbes Infect Inst Pasteur. 2001;3:585-94.

12. Spaulding AR, Salgado-Pabón W, Merriman JA, Stach CS, Ji Y, Gillman AN, et al. Vaccination against Staphylococcus aureus pneumonia. J Infect Dis. 2014; 209:1955-62.

13. Vandenesch F, Lina G, Henry T. Staphylococcus aureus hemolysins, bicomponent leukocidins, and cytolytic peptides: a redundant arsenal of membrane-damaging virulence factors? Front Cell Infect Microbiol. 2012;2:12

14. Anderson MJ, Lin Y-C, Gillman AN, Parks PJ, Schlievert PM, Peterson ML. Alpha-toxin promotes Staphylococcus aureus mucosal biofilm formation. Front Cell Infect Microbiol. 2012;2:64.

15. Finck-Barbançon $V$, Prévost G, Piémont $Y$. Improved purification of leukocidin from Staphylococcus aureus and toxin distribution among hospital strains. Res Microbiol. 1991;142:75-85.

16. Vu BG, Stach CS, Salgado-Pabón W, Diekema DJ, Gardner SE, Schlievert PM. Superantigens of Staphylococcus aureus From Patients With Diabetic Foot Ulcers. J Infect Dis. 2014;210:1920.

17. Ferry $T$, Thomas $D$, Genestier $A-L$, Bes $M$, Lina $G$, Vandenesch $F$, et al. Comparative prevalence of superantigen genes in Staphylococcus aureus isolates causing sepsis with and without septic shock. Clin Infect Dis Off Publ Infect Dis Soc Am. 2005:41:771-7.

18. Varshney AK, Mediavilla JR, Robiou N, Guh A, Wang X, Gialanella P, et al. Diverse enterotoxin gene profiles among clonal complexes of Staphylococcus aureus isolates from the Bronx, New York. Appl Environ Microbiol. 2009;75: 6839-49.

19. Becker K, Friedrich AW, Lubritz G, Weilert M, Peters G, Von Eiff C. Prevalence of genes encoding pyrogenic toxin superantigens and exfoliative toxins among strains of Staphylococcus aureus isolated from blood and nasal specimens. J Clin Microbiol. 2003;41:1434-9.

20. Xie Y, He Y, Gehring A, Hu Y, Li Q, Tu S-l, et al. Genotypes and toxin gene profiles of Staphylococcus aureus clinical isolates from China. PLoS One. 2011:6, e28276.

21. Shukla SK, Karow ME, Brady JM, Stemper ME, Kislow J, Moore N, et al. Virulence genes and genotypic associations in nasal carriage, communityassociated methicillin-susceptible and methicillin-resistant USA400 Staphylococcus aureus isolates. J Clin Microbiol. 2010:48:3582-92.

22. Van Trijp MJCA, Melles DC, Snijders SV, Wertheim HFL, Verbrugh HA, van Belkum A, et al. Genotypes, superantigen gene profiles, and presence of exfoliative toxin genes in clinical methicillin-susceptible Staphylococcus aureus isolates. Diagn Microbiol Infect Dis. 2010;66:222-4.

23. Derzelle S, Dilasser F, Duquenne M, Deperrois V. Differential temporal expression of the staphylococcal enterotoxins genes during cell growth Food Microbiol. 2009;26:896-904.

24. Burian M, Rautenberg M, Kohler T, Fritz M, Krismer B, Unger C, et al. Temporal expression of adhesion factors and activity of global regulators during establishment of Staphylococcus aureus nasal colonization. J Infect Dis. 2010;201:1414-21.

25. Schlievert PM, Case LC, Strandberg KL, Abrams BB, Leung DYM. Superantigen profile of Staphylococcus aureus isolates from patients with steroid-resistant atopic dermatitis. Clin Infect Dis Off Publ Infect Dis Soc Am. 2008;46:1562-7.

26. Sakai F, Ihara H, Aoyama K, Igarashi H, Yanahira S, Ohkubo T, et al. Characteristics of enterotoxin $\mathrm{H}$-producing Staphylococcus aureus isolated from clinical cases and properties of the enterotoxin productivity. J Food Prot. 2008;71:1855-60.

27. Aguilar JL, Varshney AK, Wang X, Stanford L, Scharff M, Fries BC. Detection and measurement of staphylococcal enterotoxin-like K (SEl-K) secretion by Staphylococcus aureus clinical isolates. J Clin Microbiol. 2014;52:2536-43.

28. Li M, Cheung GYC, Hu J, Wang D, Joo H-S, Deleo FR, et al. Comparative analysis of virulence and toxin expression of global community-associated methicillin-resistant Staphylococcus aureus strains. J Infect Dis. 2010;202: 1866-76.

29. Hamilton SM, Bryant AE, Carroll KC, Lockary V, Ma Y, Mclndoo E, et al In vitro production of panton-valentine leukocidin among strains of methicillin-resistant Staphylococcus aureus causing diverse infections. Clin Infect Dis Off Publ Infect Dis Soc Am. 2007;45:1550-8.

30. Sharma-Kuinkel BK, Wu Y, Tabor DE, Mok H, Sellman BR, Jenkins A, et al. Characterization of alpha-toxin hla gene variants, alpha-toxin expression levels, and levels of antibody to alpha-toxin in hemodialysis and postsurgical patients with Staphylococcus aureus bacteremia. J Clin Microbiol. 2015; 53:227-36.

31. Bartels MD, Petersen A, Worning $P$, Nielsen JB, Larner-Svensson $H$, Johansen $H K$, et al. Comparing whole-genome sequencing with Sanger sequencing for spa typing of methicillin-resistant Staphylococcus aureus. J Clin Microbiol. 2014;52:4305-8

32. Enright MC, Day NP, Davies CE, Peacock SJ, Spratt BG. Multilocus sequence typing for characterization of methicillin-resistant and methicillin-susceptible clones of Staphylococcus aureus. J Clin Microbiol. 2000;38:1008-15.

33. Banks MC, Kamel NS, Zabriskie JB, Larone DH, Ursea D, Posnett DN. Staphylococcus aureus express unique superantigens depending on the tissue source. J Infect Dis. 2003:187:77-86.

34. Stich N, Model N, Samstag A, Gruener CS, Wolf HM, Eibl MM. Toxic shock syndrome toxin-1-mediated toxicity inhibited by neutralizing antibodies late in the course of continual in vivo and in vitro exposure. Toxins. 2014;6:1724-41.

35. Kantor L, Fackrell HB. Senescent erythrocytes exhibit a single-hit response to staphylococcal alpha toxin. Gerontology. 1998:44:26-31.

36. Marucci AA. Mechanism of action of staphylococcal alpha-hemolysin. I. Some factors influencing the measurement of alpha-hemolysin. J Bacteriol. 1963:86:1182-8.

37. O'Reilly M, Kreiswirth B, Foster TJ. Cryptic alpha-toxin gene in toxic shock syndrome and septicaemia strains of Staphylococcus aureus. Mol Microbiol. 1990;4:1947-55. 
38. Thomas DY, Jarraud S, Lemercier B, Cozon G, Echasserieau K, Etienne J, et al. Staphylococcal enterotoxin-like toxins U2 and V, two new staphylococcal superantigens arising from recombination within the enterotoxin gene cluster. Infect Immun. 2006;74:4724-34.

39. Rieg S, Jonas D, Kaasch AJ, Porzelius C, Peyerl-Hoffmann G, Theilacker C, et al. Microarray-based genotyping and clinical outcomes of Staphylococcus aureus bloodstream infection: an exploratory study. PLoS One. 2013;8:e71259.

40. Strandberg KL, Rotschafer JH, Vetter SM, Buonpane RA, Kranz DM, Schlievert PM. Staphylococcal superantigens cause lethal pulmonary disease in rabbits. J Infect Dis. 2010;202:1690-7.

41. Pragman AA, Yarwood JM, Tripp TJ, Schlievert PM. Characterization of virulence factor regulation by SrrAB, a two-component system in Staphylococcus aureus. J Bacteriol. 2004;186:2430-8.

42. Okumura K, Shimomura Y, Murayama SY, Yagi J, Ubukata K, Kirikae T, et al. Evolutionary paths of streptococcal and staphylococcal superantigens. BMC Genomics. 2012;13:404.

43. Wilson GJ, Seo KS, Cartwright RA, Connelley T, Chuang-Smith ON, Merriman $J A$, et al. A novel core genome-encoded superantigen contributes to lethality of community-associated MRSA necrotizing pneumonia. PLoS Pathog. 2011;7:e1002271.

44. Ji G, Beavis R, Novick RP. Bacterial interference caused by autoinducing peptide variants. Science. 1997;276:2027-30.

45. Salgado-Pabón W, Herrera A, Vu BG, Stach CS, Merriman JA, Spaulding AR, et al. Staphylococcus aureus $\beta$-toxin production is common in strains with the $\beta$-toxin gene inactivated by bacteriophage. J Infect Dis. 2014;210: 784-92.

46. Chow AW, Gribble MJ, Bartlett KH. Characterization of the hemolytic activity of Staphylococcus aureus strains associated with toxic shock syndrome. J Clin Microbiol. 1983;17:524-8.

47. Schlievert PM, Osterholm MT, Kelly JA, Nishimura RD. Toxin and enzyme characterization of Staphylococcus aureus isolates from patients with and without toxic shock syndrome. Ann Intern Med. 1982;96(6 Pt 2):937-40.

48. Christensson B, Hedström SA. Biochemical and biological properties of Staphylococcus aureus septicemia strains in relation to clinical characteristics. Scand J Infect Dis. 1986;18:297-303.

49. Clyne M, De Azavedo J, Carlson E, Arbuthnott J. Production of gammahemolysin and lack of production of alpha-hemolysin by Staphylococcus aureus strains associated with toxic shock syndrome. J Clin Microbiol. 1988; 26:535-9.

50. Li S, Arvidson S, Möllby R. Variation in the agr-dependent expression of alpha-toxin and protein A among clinical isolates of Staphylococcus aureus from patients with septicaemia. FEMS Microbiol Lett. 1997;152:155-61.

51. DeLeo FR, Kennedy AD, Chen L, Bubeck Wardenburg J, Kobayashi SD, Mathema B, et al. Molecular differentiation of historic phage-type 80/81 and contemporary epidemic Staphylococcus aureus. Proc Natl Acad Sci U S A. 2011;108:18091-6.

52. Holmes NE, Turnidge JD, Munckhof WJ, Robinson JO, Korman TM, O'Sullivan MVN, et al. Genetic and molecular predictors of high vancomycin MIC in Staphylococcus aureus bacteremia isolates. J Clin Microbiol. 2014;52:3384-93.

53. Xiong YQ, Willard J, Yeaman MR, Cheung AL, Bayer AS. Regulation of Staphylococcus aureus alpha-toxin gene (hla) expression by agr, sarA, and sae in vitro and in experimental infective endocarditis. J Infect Dis. 2006;194: 1267-75.

54. Berube BJ, Bubeck Wardenburg J. Staphylococcus aureus a-toxin: nearly a century of intrigue. Toxins. 2013:5:1140-66.

55. Nilsson IM, Hartford O, Foster T, Tarkowski A. Alpha-toxin and gamma-toxin jointly promote Staphylococcus aureus virulence in murine septic arthritis. Infect Immun. 1999;67:1045-9.

56. Muñoz-Planillo R, Franchi L, Miller LS, Núnez G. A critical role for hemolysins and bacterial lipoproteins in Staphylococcus aureus-induced activation of the Nlrp3 inflammasome. J Immunol Baltim Md 1950. 2009;183:3942-8.

57. Spaan AN, Reyes-Robles T, Badiou C, Cochet S, Boguslawski KM, Yoong P, et al. Staphylococcus aureus targets the Duffy Antigen Receptor for Chemokines (DARC) to Lyse Erythrocytes. Cell Host Microbe. 2015;18:363.

58. Bergdoll MS. Importance of staphylococci that produce nanogram quantities of enterotoxin. Zentralblatt Für Bakteriol Int J Med Microbiol. 1995;282:1-6.

59. Salgado-Pabón W, Breshears L, Spaulding AR, Merriman JA, Stach CS, Horswill AR, et al. Superantigens are critical for Staphylococcus aureus Infective endocarditis, sepsis, and acute kidney injury. mBio 2013, 4. doi:10.1128/mBio.00494-13

\section{Submit your next manuscript to BioMed Central and we will help you at every step:}

- We accept pre-submission inquiries

- Our selector tool helps you to find the most relevant journal

- We provide round the clock customer support

- Convenient online submission

- Thorough peer review

- Inclusion in PubMed and all major indexing services

- Maximum visibility for your research

Submit your manuscript at www.biomedcentral.com/submit 